O fato da lei penal situar num ou noutro setor os diversos crimes, segundo o fim específico visado pelo agente, de que resulta a objetividade jurídica do próprio crime, consulta à necessidade de erigir um critério de classificação, mas não significa a impossibilidade do mesmo crime ser perpetrado, simultâneamente, contra diverso bem jurídico, atingido, ainda que de modo eventual, pela ação primária, cuja fôrça causal, conhecida do agente, compreendia o resultado plurilesivo.

O preceito constitucional quis dar ao júri o julgamento de todos os crimes em que a vida constitui, isoladamente ou em concurso com outro bem jurídico, a "ratio" incriminadora, desde que a lesão à vida esteja na esfera do dolo propulsor do delito.

A Constituição se apegou a um critério subjetivo para fixar a competência do júri.

A existência dêsse elemento subjetivo do crime depende sempre de ampla investigação, através das circunstâncias e dos fatôres, os mais diversos.

Só, no julgamento da causa, depois de reunidos todos os elementos elucidativos da dinâmica íntima do delito, muitas vêzes equívoca na sua morfologia, será possível apurar devidamente qual o verdadeiro elemento subjetivo: se o dolo ou a culpa "strictu sensu", fôrças morais propulsoras do crime.

Logo, a competência do júri deverá orientar-se, principalmente, pelo aspecto exterior do delito, desde que dêle se possa inferir razoàvelmente a existência do dolo contra a vida.

No caso de dúvida, o processo deve sempre ser atribuído ao júri, o que não impede que êste se declare incompetente, se dos debates resultar a prova de que, na espécie em julgamento, não se configurara, na realidade, um delito doloso contra a vida.

O júri é uma das garantias que protegem os direitos de liberdade da pessoa, declarados pela Constituição.

A lei modera - escreve Carlos Maximiliano - mas também tutela prerrogativa suprema do homem: se a limitação não é certa, se oferece margem a dúvidas por falta de clareza ou por impropriedade da linguagem, interpreta-se contra a restrição, a favor da liberdade.

\section{DOIS PROBLEMAS CONSTITUCIONAIS}

\author{
Ruy Cirne Lima
}

A elaboração da Constituição do Rio Grande do Sul propôs aos estudiosos o problema da constitucionalidade, face à Carta $\mid F$ ederal, do parlamentarismo nos Estados; e, do mesmo passo, a questão da competência para o desatamento do conflito que assim se vinha a criar entre o texto constitucional do Estado e o da União, nesse particular.

Consabida é a solução dada às duas controvérsias pelo Supremo Tribunal Federal que, reconhecendo-se competente e, pois, conhe cendo da tese "in abstracto", pronunciou a inconstitucionalidade das disposições da Constituição Estadual, de enderêço parlamentarista.

Diante dêsse aresto, e de outros, quanto à questão da competência, fiéis à mesma orientação, poderiam, talvez, considerar-se encerradas as duas questões. Pensamos, não obstante, nos possa ser perdoada a audácia de volvermos sôbre elas. Quanto ao mérito, entendemos que, de alguma forma, nos excusa a circunstância de que os argumentos, dos quais nos servimos, não entraram diretamente em discussão, ao menos em quanto se conhece, publicado, acêrca da controvérsia. Quanto à questão da competência para a solução do conflito, atemua-nos a ousadia o fato de que, depois de ter recusado a Washington, um pronunciamento "in abstracto", a Suprema Côrte dos Estados Unidos consentiu em dá-lo mais tarde, ainda que extraoficialmente, por solicitação de Monroe, para, sòmente depois, fixar-se definitivamente na posição negativa, hoje característica fundamental do sistema judiciário norte-americano. (Charles Evans Hughes, La Suprema Corte de los Estados Unidos, trad. de R. M. Pasqual e V. Herrero, México, s. d., pág. 47).

Esta, a explicação indispensável como proêmio aos dois estudos que seguem, ambos de elaboração anterior ao aresto do Supremo Tribunal Federal e o primeiro dos quais, de resto, já publicado. 
O REGIME PRESIDENCIAL E OS PRINCÍPIOS CONSTITUCIONAIS DA UNIÃO

A quem analisa o conteúdo do artigo 7 , inciso VII, da Constituição Federal, o que, para logo, ocorre é o caráter meramente remissivo das enunciações nêle contidas. Referem-se, - deixemos de parte, por enquanto, a da letra " $b$ ", - referem-se tôdas as mais a disposições, alhures, insertas na própria Constituição.

A forma republicana representativa, sabemos todos no que consiste. Tradicional entre nós é o conceito de Rui Barbosa, segundo o qual consiste a forma republicana em que "sôbre existirem os três poderes constitucionais, o Legislativo, o Executivo e o Judiciário, os: dois primeiros derivem realmente de eleição popular" (1). À sua vez, o regime representativo não é senão "o regime em que o govêrno é exercido por mandatários, representantes escolhidos pelo povo, agindo pelo povo soberano, e em nome dêle". Aqui, ainda, a lição é tradicional na publicística brasileira: vem-nos de João Barbalho ( ${ }^{2}$. $\mathrm{O}$ conteúdo da letra "a" do artigo 7 , inciso VII, da Constituição, achâmo-lo, porém, na própria Constituição. No mesmo artigo 7 , inciso VII, afirma-se já o princípio da eletividade do Governador, ao proibir-se-lhe a reeleição (art. 7, VII, "d"). No artigo 139, incisos II e V, - a eletividade do Governador e do Legislativo Estadual é o pressuposto declarado das inelegibilidades que, para tais órgãos, a Constituição estabelece. Fixa-se, destarte, no próprio texto federal, que o Executivo e o Legislativo do Estádo hão de promanar, realmente, de acôrdo com a lição clássica, da eleição popular. No Ato das Disposições Constitucionais Transitórias, o artigo $2, \S 3$, caracteriza a natureza representativa dos múnus exercidos pelo Governador e pela Assembléia Legislativa Estadual. Aí se diz explicitamente: "Os mandatos dos governadores e dos deputados às Assembléias Legislativas..." Trata-se, pois, de mandatários do povo, como cabe em um regime representativo. Próprio dêste é, ainda, a temporariedade das funções eletivas. O Ato das Disposições Constitucionais Transitórias esgota, quanto à primeira investidura, o conteúdo do princípio, fixando, naquele mesmo artigo $2, \S 3$, o têrmo final dos mandatos do Governador e dos Deputados à Assembléia Legislativa, em tal hipótese. Quanto ao futuro, o artigo 7, inciso VII, êle próprio, enuncia a regra, a ser observada: "temporariedade das funções eletivas, limitada a duração destas à das. funções federais correspondentes" (letra "c").

Conseqüentemente, só no tocante à forma republicana representativa (letra "a"), remete-nos o artigo 7, inciso VII, às alíneas "c"

(1) Comentários à Constituição Federal Brasileira, coligidos e ordenados por Homero

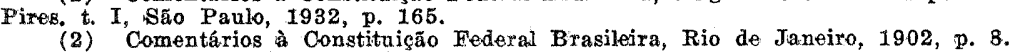

e "d" do mesmo inciso, ao artigo 139, incisos II e V, da Constituição e ao artigo $2, \S 3$, do Ato das Disposições Transitórias.

$\mathrm{Na}$ letra " $\mathrm{c}$ ", o inciso VII do artigo 7 vai referido, a seu turno, à letra "a" do mesmo inciso e aos artigos $57,60, \S 2$, e 82 da Constituição, com a restrição "pro tempore" do artigo 2, §3, do Ato das Disposições Constitucionais Transitórias. $\mathrm{Na}$ verdade, os mandatos de Deputado e (adotada a bi-cameralidade) de Senador do Estado não poderão ter duração superior à fixada para os dos Deputados (art. 57), ou para os dos Senadores federais (art. 60, $\$ 2$ ); nem o mandato do Governador poderá exceder no tempo ao do Presidente da República (art. 82), salva a disposição transitória (art. 2, § 3), que faz coincidirem, quanto ao têrmo final, o mandato do atual Presidente da República, do atual Governador do Estado e os dos atuais Deputados à Assembléia Legislativa.

Na letra "d", o inciso VII do artigo 7 reporta-se à disposição do artigo 139, II, “a", da Constituição. Por esta última disposição, inelegível é, para Governador do Estado, "o Governador que haja exercido o cargo, por qualquer tempo, no período imediatamente anterior". Aquí se diz que o Governador é inelegível para o período governamental imediato; ali, proíbe-se a reeleição "para o período imediato". A remissão é evidente.

Na letra "e", o inciso VII do artigo 7, ao prescrever aos Estados o princípio da autonomia municipal, limita-se, por igual, a uma indicação remissiva à própria Constituição: o conceito de autonomia municipal, o intérprete irá buscá-lo aos artigos 23 e 28 do texto.

Na letra "g" (anteponhâmo-la à letra " $\mathrm{f}$ "), acêrca das garantias do Poder Judiciário, o inciso VII do artigo 7 endereça-nos ao Título II da Constituição ( $\mathrm{Da}$ Justiça dos Estados), cujo único artigo 124 regula minudentemente a matéria; senão, também, ao artigo 128 do Título III, no que respeita à organização do Ministério Público Estadual.

A letra " $f$ " do mesmo inciso é, face às que já examinamos, a que maior liberdade, na fixação do respectivo conteúdo, espaça ao Estado. Essa liberdade, porém, decorre, - não da ausência de remissão complementar, ao texto da Constituição, - e, sim, ao contrário, da latitude da disposição, a que remete, a qual, de sua parte, nos reenvia ao que fôr estabelecido na Constituição Estadual. Tal disposição é a do artigo 22 da Constituição Federal: "A administração financeira, especialmente a execução do orçamento, será fiscalizada... nos Estados... pela forma que fôr estabelecida nas Constituições Estaduais".

Visto, pois, e claramente visto está que as alíneas "a", "c", "d", "e", " $\mathrm{f}$ ", "g" do artigo 7, inciso VII, têm o seu conteúdo determinado, alhures, no próprio texto da Constituição Federal, ou do Ato das Disposições Constitucionais Transitórias. 
Cânon da exegese constitucional é, de outro lado, o princípio, segundo o qual "a construção de um dispositivo constitucional deve ser uniforme" $\left({ }^{3}\right)$. A conclusão que se nos oferece, já agora, é a de que, também, a alínea "b" do mesmo artigo 7 , inciso VII, dentro da construção sistemática do dispositivo, encerra, uniformemente, uma enunciação remissiva.

Depara-se-nos desde logo, sem dificuldade, a disposição, a que o princípio da "independência e harmonia dos poderes" (art. 7, VII, “a”), ali prescrito aos Estados, vai referido. E' a disposição do artigo 36 da Constituição: "São Poderes da União o Legislativo, o Executivo e o Judiciário, independentes e harmônicos entre si".

A coincidência conceitual das duas fórmulas, - "independência e harmonia dos poderes" e "poderes independentes e harmônicos entre si”, - impõe a convicção de uma recíproca remissão e correspondência entre êsses dois passos da Constituição. $O$ conteúdo do princípio de independência e harmonia entre os poderes, inserto na alínea "b" do artigo 7, inciso VII, não poderá ser senão o que resulta da organização política federal, cujos três poderes, a mesma Constituição, ela própria, qualifica decisivamente como "independentes e harmônicos entre si".

Há, de resto, na Constituição Federal, - em outros dispositivos - atestam, - uma prefiguração da estrutura política do Estado, no tocante, sobretudo, à divisão dos poderes. Na Constituição de 1891 , já a havia. Quanto à tripartição dos poderes, João Barbalho observou, oportunamente: "A Constituição Federal tem por existentes no organismo político de cada Estado os referidos três poderes, e a êstes se refere, separadamente" $\left({ }^{4}\right)$. Na Constituição de 1946, a tripartição dos poderes políticos do Estado acha-se delineada no artigo 9 III, e no artigo 7, VII, "g"; aquêle, aludindo ao Poder Legislativo e ao Poder Executivo do Estado; êste último, ao Poder Judiciário. Não seria lícito, portanto, ao Estado adotar outra fórmula de divisão dos poderes, com maior ou menor número dêles.

Nessa prefiguração da morfologia política dos Estados, a Constituição Federal vai além. Nos $\$ \S 1$ e 2 do artigo 28 , o texto constitucional refere-se à nomeação de prefeitos pelo Governador do Estado: no primeiro parágrafo, a título de faculdade; no segundo, imperativamente. Tal faculdade, reservada ao Estado, como restrição à autonomia municipal, a Constituição situa-lhe, porém, o exercício nas mãos do Governador. Certo, não se presume que a Constituição Federal tenha, aí, pretendido invadir a esfera da autonomia do Estado, e prescrever-lhe regras internas de competência. $O$ que a Constituição visou, é claro, foi atribuir ao Executivo Estadual, em tal hipótese, a nomeação dos prefeitos. Se disse, ao invés de Executivo, Governador, a razão é simples: é que a Constituição Federal, nessa disposição, pressupôs a organização política do Estado modelada pelo presidencialismo federal. O Governador, supôs a Constituição Federal, é, no Estado, o que é o Presidente da República na União; e nesta, a exemplo dos Estados Unidos, "o Presidente é o SO possuidor de TODOS os poderes necessários à realização das funções executivas" (5).

À conclusão de que, em tais têrmos, o regime presidencial é prescrito ao Estado pela Constituição Federal, opõe-se, entretanto, o entendimento diverso, que predominou durante os trabalhos da Assembléia Nacional Constituinte. A significação dos trabalhos preparatórios e dos materiais legislativos, para a interpretação constitucional, é, sem embargo, nenhuma, se o texto e a sua construção sistemática não lhes dão apoio. Carlos Maximiliano recorda, a propósito, que, "nos Estados Unidos, os tribunais aceitaram uma exegese consentânea com o texto, embora certo se tornasse que contrariavam a intenção evidente dos autores do código fundamental; êstes remediaram o mal inesperado com adotar sucinta e unânimemente a undécima emenda, que pôs têrmo à jurisprudência desoladora, porém certa" ( $\left.{ }^{6}\right)$.

\section{A INTERVENÇÃO NOS ESTADOS POR INOBSERVÂNCIA} DOS PRINCÍPIOS CONSTITUCIONAIS DA UNIÃO

Valiosa, sôbre a matéria, é a lição de Herculano de Freitas, que Ernesto Leme oportunamente nos recorda: "O desrespeito aos princípios constitucionais da União, observa Herculano de Freitas ( $R e-$ vista dos Tribunais, $47 / 73$ ), pode ser de fato e de direito. De fato, "se o Estado embaraçar, por atos materiais, o exercício dêsses direitos'; de direito, 'se o Estado elaborar leis contrárias a essas disposições, negando em leis locais êsses direitos afirmados pela Constituição Federal" " $\left({ }^{1}\right)$.

Dois, conseqüentemente, são os meios, pelos quais a inobservância dos princípios constitucionais da União pode vir a manifestar-se: a lei, na qual se abrangerão a Constituição e as leis ordinárias estaduais; e o ato, em sentido material, isto é, a atividade concreta $e$ individualizada do Estado, ou jurisdicional, ou administrativa. Hans Kelsen explica-nos o conteúdo da distinção: "Na função legislativa, o Estado estabelece regras gerais abstratas; na jurisdição e na administração, desenvolve uma atividade individualizada, desem-

(5) Jacques Lambert, Histoire Constitutionnele de l'Union Americaine, t. I, 1930, p. 233. 2930, p. 233. (1) E. Leme, A Intervenção Federal nos Estados, 'São Paulo, 1930, n.o 179, nota
212 , p. 153 . 
penha tarefas concretas" $\left({ }^{2}\right)$. Deixemos de parte, porém, os atos jurisdicionais, embora êstes possam importar, também, inobservância dos princípios constitucionais da União: contra atos tais, a mesma Constituição oferece o remédio do recurso extraordinário, cabível, segundo o estatuto federal, "quando a decisão fôr contrária a dispositivo desta Constituição" (art. 101, III, a).

Dois, correspondentemente, hão de ser os métodos de verificação da inobservância dos princípios constitucionais da União: "in abstracto", quando ela constar meramente de normas jurídicas, como a Constituição e as leis ordinárias estaduais; "in concreto", quando ela se manifestar por via de atos, em sentido material.

A verificação “in abstracto", supõe o exame da norma jurídica, enquanto norma jurídica, sem consideração dos efeitos que pode produzir ou, seja, das relações jurídicas que podem vir a estabelecer-se, modificar-se ou extinguir-se, pela sua execução. A verificação "in concreto", diversamente, supõe o exame dos efeitos do ato do Estado, na órbita das relações definidas e garantidas pela ordem jurídica.

Tendo como conteúdo uma norma ou proposição jurídica, a lei, constitucional ou ordinária, precisa ser executada para produzir efeito: antes disso, como Duguit sinala, "elle est une règle générale et abstraite par laquelle l'Etat n'entre pas en relation avec les autres personnalités" ${ }^{3}$ ). Já, ao contrário, o ato, em sentido material, conceitua-se pelos seus efeitos, pela sua finalidade imediata, dirigida à criação, modificação ou extinção de relações jurídicas (art. 81, Cód. Civ.).

A determinação "in abstracto" da constitucionalidade de uma norma jurídica é, pois, meramente um problema de interpretação da Constituição e da norma, ao passo que a determinação "in concreto", face a uma relação jurídica, da constitucionalidade de um ato, em sentido material, é um problema de interpretação e de aplicação da Constituição.

A interpretação consiste em "determinar o sentido e o alcance das expressốes do direito" (4); a aplicação, "no enquadrar um caso concreto em a norma jurídica adequada" $\left({ }^{5}\right)$. Esta última é, por excelência, função do Poder Judiciário que, em forma conclusiva e terminante, aplica o direito vigente aos casos concretos. Aquela, meramente uma técnica de investigação jurídica.

A aplicação do direito cabe na competência do Poder Judiciário e a interpretação precederá a aplicação da norma jurídica ao caso

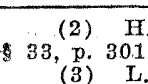

p. 301 . Kelsen, Teoria General del Estado, trad. de L. L. Lacambra, Madrî, 1934,

(3) L. Duguit, Traité de Droît Constitutionnel, t. III, Paris, 1930, \& 86, p. 554 .

w. a, p. 5. Maximiliano, ob. eit., n.o 8, p. 11.
}

concreto. Mas a só interpretação "qua talis" exorbita da competência judiciária, ainda que se trate de matéria constitucional.

Rui Barbosa disse, excelentemente: "Os tribunais não discutem êsses assuntos "in abstracto", sôbre proposições gerais. Não intervêm na elaboração da lei, nem na sua aplicação geral. Não são órgãos consultivos nem para o legislador, nem para a administração. Sabe-se como em 1793 se baldou a tentativa de Washington, solicitando à Suprema Côrte um parecer. A justiça não é auxiliar dos que decretam a lei, nem dos que a executam" ( $\left.{ }^{6}\right)$.

Ter-se-á a Constituição Federal apartado dêsses princípios, ao prescrever o que se dispõe no $\S$ único do artigo 8?

Aí se dispõe:

'No caso do n. ${ }^{\circ}$ VII (inobservância dos princípios constitucionais da União), o ato argüido de inconstitucionalidade será submetido pelo Procurador-Geral da República ao exame do Supremo Tribunal Federal e, se êste a declarar, será decretada a intervenção'.

O pronunciamento do Supremo Tribunal Federal, nessa hipótese, não exorbita, entretanto, de sua função judicativa, tal a processualística a conceitua. Trata-se, aí, e claramente, de um prejulgado constitucional.

A nossa processualística assim caracteriza o prejulgado, no artigo 861 do Código de Processo Civil: "A requerimento de qualquer dos seus juízes, a Câmara ou turma julgadora poderá promover o pronunciamento prévio das Câmaras reunidas, sôbre a interpretação de qualquer norma jurídica, se reconhecer que, sôbre ela, ocorre ou poderá ocorrer divergência de interpretação entre Câmaras ou turmas".

Pronunciamento semelhante, - prévio à aplicação do direito ao caso concreto, - é o que a Constituição comete ao Supremo Tribunal Federal na disposição do artigo 8 , § único.

Tem êsse prejulgado, como o do direito processual, a finalidade evidente de solver "a priori" qualquer divergência possível de interpretação, entre o Poder Legislativo e o Poder Judiciário, face à Constituição Federal. Essa divergência, contudo, sòmente poderá ocorrer, se, além de submetida ao juízo político, que a intervenção traduz, a mesma matéria vier a ser sujeita ao Poder Judiciário, como objeto de um litígio. Tal como o prejulgado do direito processual, o prejulgado constitucional supõe, portanto, um litígio, - uma aplicação do direito ao caso concreto, - à qual meramente antecipa a solução da questão de interpretação.

Pressuposto do prejulgado constitucional é, realmente, um ato, em sentido material, "argüido de inconstitucionalidade". E' o que (6) Rui Barbosa, A Constituięão e os Atos Inconstitucionais, Rio de Janeiro, 2.a
ads . d., p. 107 . 
\$ único do artigo 8 claramente diz. "Ato" significará, nesse dispositivo, a operação, formal e materialmente tal, de qualquer dos três poderes do Estado, - do Legislativo, do Executivo e do Judiciário? texto constitucional responde negativamente à pergunta. Aos atos jurición às suas disposicões, "dic̃e" (art 101, IIT, a) Constituição refere-se, chamando-lhes "decisões" (art. 101, III, a) e oferecendo, de resto, contra êles, o remédio específico do recurso extraordinário, o que os exclui da compreensão do artigo 8 , § único De outra parte, a mesma Constituição, no artigo 101, III, c, indica distinta e separadamente, como suscetíveis de oposição ao estatuto federal, a "lei ou ato do govêrno local". E ainda, no artigo 13, em complemento ao $\S$ único do artigo 8 , formula explicitamente a hipócose de que a suspensão da execuão do ato argüido de inconstituciotese de qualidade no Estado, nalidade baste para o restabelecimento da normadid - o que, sem sombra de dúvida, não se pode referir a normas jurí dicas "in abstracto". Na verdade, uma norma jurídica poderá conter, em si mesma, uma anormalidade; mas nunca poderá "in abstracto" ex sil; nem, à sua vez, a anormalidade, acaso ǵnsita na norma, poderá desaparecer com a suspensão de sua execução.

Resulta, do que levamos dito, que o $\S$ único do artigo 8 não desnatura a função própria do Poder Judiciário. Cria-se, nesse dispositivo, a figura jurídica do prejulgado constitucional, restrita, porém, ao pressuposto de um ato, em sentido material, que, por inobservância dos princípios constitucionais da União; de um lado, imponha a providência política da intervenção e, de outro, pelos efeitos ponha a providencia politica da intervenção e, de ha afetado, possa vir produzidos sôbre as relações jurídicas, que tenha afetado, possa vir a reclamar a atuação restauradora do Poder Judiciário. Sem êsse pressuposto, o $§$ único do artigo 8 não pode ser invocado.

Quando se trate, pois, de norma jurídica "in abstracto", - da Constituição ou de leis ordinárias estaduais, ainda sem execução, a intervencão federal ficará excluída, pôsto-que manifesta a inobservância dos princípios constitucionais da União?

A intervenção certamente não estará excluída nessa hipótese, mas a disposição que a regerá, será a do artigo 8, princípio:

"A intervenção será decretada por lei federal nos casos dos ns. VI e VII do artigo anterior".

Apenas, o $\S$ único do artigo 8 e o artigo 13 não lhe serão aplicáveis.

Essa solução, convém que acrescentemos, não é sòmente fruto da exegese. A própria doutrina qualifica como legislação, em sena exese. A o pronunciamento "in abstracto" sôbre a conformidade, ou não, de uma norma jurídica com a Constituição. Assim Ernst
Friesenhahn: Sie gehört in den Bereich der materiellen Staatsfunktion Gesetzgebung" ( 7 ).

A mesma solução caberá, também, analògicamente, nos casos puramente políticos, nos quais o ato, em sentido material, que acaso dê execução a norma jurídica do Estado, contrária aos princípios constitucionais da União, escapará, por sua natureza, à competência e ao conhecimento do Poder Judiciário $\left({ }^{8}\right)$.

Podemos, já a esta altura, assentar as nossas conclusões:

1. o § único do artigo 8 e a disposição complementar do artigo. 13 sòmente são aplicáveis, quando se trate de ato, em sentido material, no qual se traduza a inobservância dos princípios constitucionais da União, e contanto que possa, concomitantemente, vir a ser sujeito, como objeto de litígio, à decisão do Poder Judiciário;

2. quando se trate de norma jurídica estadual, constitucional ou ordinária, a ser confrontada "in abstracto", com a Constituição Federal, ou quando se trate de caso puramente político, o pronunciamento sôbre a inconstitucionalidade competirá ao Poder Legislativo. da União, que o formulará, implícita ou explìcitamente, ao decretar a intervenção (art. 8, princ.).

Alguns aspectos secundários, mas não despiciendos, das questões. versadas merecem destaque, ainda.

Se, para o pronunciamento do Poder Judiciário, qualquer ato argüido de inconstitucionalidade pode oferecer matéria suficiente, tanto não acontece, face ao juízo político da intervenção.

A justificar a intervenção, é necessário que a inobservância dos, princípios constitucionais da União se manifeste na atividade do Estado, de modo substancial, e não meramente acidental.

$\mathrm{O}$ ato, capaz de justificar a intervenção, há de ser, portanto, a: execução de disposição da Constituição ou de lei ordinária estadual; e a sua significação política advir-lhe-á, precisamente, da generalidade e da permanência da Constituição ou da lei, de que êle fôr -a concretização.

A generalidade e a permanência da Constituição ou da lei estadual configuram, diante da União, uma atitude fundamental do Estado; e no em que traduzirem a inobservância dos princípios constitucionais da União, uma secessão virtual da federação.

(7) E. Friesenhahn, Die Staatsgerichtsbarkeit, no Handbuch des Deutschen Staatshohts, de G. Anschutz e R. Thoma, t. II, Tübingen, 1932, \& 98, p. 526. Cf., quanto. aos Estados Unidos, Charles Evans Hughes, La Suprema Corte d.

(8) Cf. Rui Barbasa, ob. cit., p. 148 e 149 
De outra parte, ao aludirmos aos atos administrativos, a que o artigo $8 \S$ único diz respeito, frisamos, sempre, que nos referíamos a atos, em sentido material.

Parece excusado acrescentar que o ato administrativo em sentido material, nem sempre é obra do Poder Executivo. Oreste Ranelletti oferece-nos, nesse particular, o ensinamento clássico: “dagli organi legislativi, sia singolarmente che colletivamente, quindi in questo secondo caso nella forma della legge, e dagli organi giudiziari, e da quelli administrativi, possono essere emanati atti amministrativi in senso materiale" $\left({ }^{9}\right)$

\section{U M A L I Ç Ã O D E R U I}

\section{Hernani Estrella}

Há 36 anos, em pleito memorável, assim pela significação econômica, na época, como pela relevância jurídica das questões suscitadas e, ademais, pela autoridade inconteste do patrono da parte. autora, o consagrado comercialista pátrio, José Xavier Carvalho de Mendonça, - Rui, atuando como advogado dos réus, deu inesquecível lição sôbre palpitante e ainda hoje controvertido tema de direito comercial.

No impresso em que inseriu as notáveis razões de defesa de seus constituintes, e mercê das quais logrou vitória retumbante definitiva, perante o Supremo Tribunal Federal, o insigne advogado condensou tôdas as questões ventiladas na demanda debaixo do título pelo qual, a partir de então, êsse trabalho tornou-se conhecido e justamente admirado $\left({ }^{1}\right)$.

Antes dêle, como ainda agora, ninguém, entre nós, abordou, por forma tão exaustiva, documentada e convincente os problemas em causa. Se, pela finalidade, pelas injunções da ocorrência e pelos deveres do ofício, o escritor soberbo não se comportou como vero monografista, que, votado à meditação e à construção teórica, se propusesse a expor, em face de princípios e de escolas doutrinárias, um tema jurídico predeterminado, nem por isso deixou de alçar-se às regiões do pensamento, de onde brotaram cintilantes reflexões. Pôsto que impelido ao exame dos fatos, nem por isso o grande jurisconsulto deu menor atenção ao deslinde das teses de direito, enunciadas uma por uma, e submetidas tôdas a percuciente análise através dos ensinamentos dos especialistas estrangeiros, da jurisprudência dos países mais evoluídos e do espírito do nosso direito.

Servindo-se, em primeira mão, de tão copioso material científico, Rui, como era de seu feitio e formação intelectual, lançou sólidas premissas e delas extraiu conclusões irrespondíveis. Daí por que muitos são os assertos que encerram verdades gerais, confrontadas e confirmadas por estudos muito posteriores.

(1) Como se sabe, o trabalho de Rui Barbosa foi publicado, pela vez primeira em 1913, com o título: "As cessôes de. Clientela e a a interdição de concorrência nas Aliega 